\title{
KONINKLIJKE BESLUITEN IN SURINAME
}

DOOR

\section{PH. A. Samson (Paramaribo)}

Suriname is thans op het gebied van eigen interne aangelegenheden autonoom. Wettelijke regelingen, die bij Koninklijk Besluit worden ingevoerd, behoren tot het verleden.

Over de wijze waarop het Opperbestuur heeft ingegrepen in aangelegenheden die tot de interne huishouding van Suriname behoorden, is veel geschreven en gesproken.

In een verdienstelijk proefschrift, op 9 Juli 1915 verdedigd aan de Rijks Universiteit te Leiden, behandelt M. A. A. J. DE NeEF De Regelingsbevoegdheid van de Kroon voor de Koloniën. In de paragraaf ,De Koning en de koloniale verordeningen van Suriname en Curaçao" geeft hij een opsomming van de ontwerpen welke krachtens het Regeringsreglement bij koloniale verordening konden worden geregeld, doch waarvoor een K.B. werd uitgelokt.

Doel van dit opstel is om na te gaan in welke gevallen en op welke wijze, van 1915 af, het Opperbestuur heeft ingegrepen in de Surinaamse aangelegenheden.

Voor een goed begrip van de zaak moge een korte uiteenzetting van de wettelijke basis, waarop dit ingrijpen rustte, voorafgaan.

In het Regeringsreglement van 1865, waarbij Suriname een volksvertegenwoordiging kreeg, werd als regel de regeling van de inwendige aangelegenheden aan de Surinaamse wetgever overgelaten. Op deze regel waren de volgende uitzonderingen toegelaten:

1. bepalingen, waardoor de toelating in de kolonie van in Nederland gedrukte stukken belemmerd wordt, behoeven bekrachtiging bij de wet (art. 8);

2. de begroting en de verantwoording der uitgaven en ont-

$$
-129-
$$


vangsten over elk dienstjaar worden bij de wet vastgesteld, indien deze begroting niet sluitend was (art. 112 en 114);

3. het muntstelsel wordt bij de wet geregeld (art. 147);

4. geldleningen ten laste van de kolonie kunnen niet worden aangegaan dan uit kracht van koloniale verhoudingen, goedgekeurd bij de wet (art. 151);

5. de wet regelt de wijze van beheer en verantwoording der koloniale geldmiddelen (art. 153).

Bij verschillende artikelen werden onderwerpen ter speciale regeling aan de Koloniale Staten opgedragen, alleen bij conflicten zou de Nederlandse wetgever kunnen ingrijpen. Van een ingrijpen van het Opperbestuur werd het eerst vernomen in 1871, toen bij de wet van 3 November 1871 (G.B. 1872 No.6) een drankbelasting in Suriname werd ingevoerd.

Een door de Gouverneur ingediende verordening tot invoering van een drankbelasting was door de Koloniale Staten verworpen, niet omdat zij bezwaar hadden tegen de regeling, doch op grond dat zij daartoe niet wensten over te gaan, zolang Nederland niet beter voldeed aan zijn verplichtingen ten aanzien van de immigratie.

De Encyclopaedie van Nederlandsch West-Indië vermeldt, dat nadien de regering niet verder voortgegaan is op die weg, omdat van gezaghebbende zijde de wettigheid van deze inmenging was betwist, op grond dat de regeling der materie aan de Koloniale verordening was opgedragen, en bij de behandeling van het Regeringsreglement zowel de Regering als de Tweede Kamer hadden verklaard als regel de autonomie der kolonie in huishoudelijke zaken te zullen eerbiedigen.

Aan deze vrijgevige en met het idee der in 1865 toegekende autonomie volkomen in overeenstemming zijnde regel, werd in 1901 een einde gemaakt. Blijkbaar heeft het conflict van de Staten met Gouverneur Jhr mr M. A. DE Savornin Lohman (1888-1891) hiertoe bijgedragen. Bij de wijziging van het Regeringsreglement bij wet van 2 Februari 1901 (st. No. 55 G.B. No. 16) wordt het later ,,berucht” geworden artikel 48 ingevoerd:

Dit artikel luidde:

,Behoudens de regelingen, bedoeld in het tweede lid van artikel 114 en in de artikelen 148 en 151, kan elk onderwerp waarin volgens dit reglement bij koloniale verordening is of kan worden voorzien, worden geregeld bij Koninklijk Besluit, genomen in den vorm, bij de Grondwet van het Koninkrijk voorgeschreven voor algemeene maatregel van bestuur. 
De koloniale verordening in wier onderwerp wordt voorzien bij de wet of bij een Koninklijk besluit als bedoeld in het eerste lid van dit artikel, vervalt op het ogenblik dat zoodanige wet of zoodanig Koninklijk besluit in de kolonie begint te werken".

Algemeen was men van oordeel dat deze wijziging van het Regeringsreglement een zware slag toegebracht aan de autonomie van Suriname; de geschiedenis heeft bewezen dat dit oordeel juist was.

De Memorie van Toelichting op de wijziging, lichtte bovenbedoelde bepaling o.m. als volgt toe:

,De wetgever van 1865 bedoelde naast den Gouverneur, die als vertegenwoordiger des Konings de kolonie bestuurt als vertegenwoordigend lichaam te stellen de Koloniale Staten, die met den Gouverneur de Wetgevende Macht zouden uitoefenen, voor zoover deze niet grondwettig aan de Wetgevende macht van de Staat of aan de Koning behoort. Hun werd daarbij gegeven recht van amendement en van initiatief; tevens werd hun toegekend recht van petitie en van interpellatie. $Z_{i j}$ verkregen deel in de bestuursmacht door medewerking tot voorlopige vaststelling - die buiten bepaalde gevallen als definitieve geldt - van de jaarlijksche koloniale huishoudelijke begrooting.

Geenszins werd bedoeld, aan de Staten toe te kennen eene zelfstandige macht, allerminst hen aan te stellen tegenover of boven den Gouverneur. Tot medewerking in den aangegeven zin werden zij geroepen. Mogen al enkele bepalingen van het Regeeringsreglement in het bijzonder die betreffende het recht van interpellatie en het recht van ontbinding, bij oppervlakkige beschouwing het denkbeeld kunnen opwekken dat de verhouding tussen de Staten en den Gouverneur eenigermate op die gelijkt tusschen de Staten-Generaal en de Regeering in het Moederland, dè gedachtenwisseling tussen Regeering over de wetsontwerpen makkt elke misvatting te dien aanzien onmogelijk.

Echter is er een niet onbelangrijk punt, dat met de bevoegdheid der koloniale Staten samenhangt, waaromtrent twijfel mogelijk is, en sedert de vaststelling van het Regeeringsreglement onzekerheid heeft bestaan. Het betreft de vraag of, waar het Regeeringsreglement bepaalt dat eene regeling moet geschieden bij koloniale verordening, hierdoor 's Konings bevoegdheid tot regeling van het onderwerp wordt uitgesloten.

Voor een bevestigend zoowel als voor een ontkennend antwoord zijn uit de discussiën, in de Tweede Kamer bij de behandeling van het Regeeringsreglement gehouden argumenten te putten. De regeering werd tot nog toe niet voor de vraag geplaatst in verband met het voornemen tot regeling van zoodanig onderwerp bij Koninklijk besluit. Het is wenschelijk te zorgen dat dit geval zich niet kan voordoen. Hoe men ook, in verband met het thans vigeerend Regeeringsreglement, over de vraag moge denken - wanneer zoodanige regeling noodig mocht blijken moet het nemen van den maatregel niet kunnen afstuiten op mogelijken twijfel omtrent de koninklijke bevoegdheid.

Die bevoegdheid behoort vast te staan. $\mathrm{Zij}$ past in het stelsel van het Regeeringsreglement. Onbevoegdheid zoude ook te rijmen zijn met 
art. 61 der Grondwet, waarbij wordt bedoeld, dat de wetgever door zelf te regelen, 's Konings bevoegdheid tot regeling kan beperken, maar dan ook uitgesloten is opdracht van wetgeving aan een andere macht, die koninklijke bevoegdheid te niet doet. Ook uit een practisch oogpunt dient de bovenstaande twijfel te worden opgeheven. Regeling bij koloniale verordening van de onderwerpen, thans daarvoor aangewezen, behoort regel te blijven.

Maar wanneer een conflict tusschen Gouverneur en Koloniale Staten zich in den vorm van verwerping eener ontwerp-verordening mocht voordoen, moet eene Koninklijke beslissing over de zaak zelve mogelijk zijn.

Ook wanneer om andere redenen eene noodige regeling bij Koloniale verordening achterwege mocht blijven, behoort zij bij Koninklijk besluit tot stand te kunnen komen."

Bij de behandeling in de Staten-Generaal kwam het Tweede Kamerlid van Kol tegen de wijziging op, doch het voorgestelde artikel werd door de Kamers aanvaard.

Blijkens de Toelichting op het ontwerp Surinaamse Staatsregeling was de Minister van Koloniën van oordeel dat het stelsel van artikel 48 zich niet verdraagt met het nieuwe artikel 61 der Grondwet, waarbij bepaald is, dat, tenzij regeling bij de wet voorbehouden is, de regeling van de inwendige aangelegenheden der overzeese gewesten moet worden overgelaten aan de aldaar gevestigde organen en dat regeling door de Koning alleen kan plaats hebben wanneer Hem daartoe bij de wet voor bepaalde onderwerpen of bepaalde gevallen de bevoegdheid is verleend.

In de op 1 April 1937 in werking getreden Surinaamse Staatsregeling verviel dan ook de blanco volmacht, in artikel 48 gegeven, en daarvoor kwam in de plaats een conflictenregeling ontleend aan de Indische Staatsregeling.

Thans willen wij nagaan in welke gevallen en onder welke omstandigheden artikel 48 is toegepast, waarna zal worden aangegeven voor welke ontwerpen de toepassing van de conflictenregeling plaats vond.

Allereerst volge hier een opsomming van de K.B.'s die - gelet op artikel 48 Regeringsreglement - in Suriname zijn ingevoerd van 1915-1937. Als uitgangspunt wordt het jaar 1915 genomen, omdat ten aanzien van de geschiedenis der materie van 1901-1915 kan worden verwezen naar het hierboven genoemd Proefschrift van DE NEEF.

1918 No. 56 Vaststelling van een nieuw octrooi voor de Surinaamsche Bank te Amsterdam.

1919 No. 1 Nadere wijziging verlofstraktementen. 
1919 No. 4 Vergunning West-Indische Cultuurbank om als creditvereniging op te treden.

1919 No. 9 Wijziging R.O. betreffende vervanging van de President van het Hof van Justitie.

1919 No. 65 Wijziging van artikel 466 Wetboek van Strafrecht betreffende het onder toezicht brengen van de overheid, van huizen van verkoop met recht van wederverkoop.

1922 No. 101 Wijziging in het Wetboek van Strafrecht van ,Surinaamsch vaartuig" in "Nederlandsch of Surinaamsch vaartuig".

1923 No. 55 Toekenning van bevoegdheid aan de Gouverneur van Suriname om tot het ondergaan van een opgelegde gevangenisstraf of hechtenis de veroordeelde naar Nederland te zenden.

1924 No. 30 Wijziging van het Burgerlijk Wetboek nopens de verantwoordelijkheid van de bewaarders der hypotheken.

1924 No. 56 Regeling van verhoging van Surinaamse pensioenen.

1924 No. 63 Regeling van de bepalingen op de overtocht van Nederland naar Suriname en omgekeerd ten laste van de Surinaamse geldmiddelen.

1925 No. 2 West-Indisch Verlofsbesluit 1924.

No. 14 West-Indisch Uitzendingsbesluit 1925.

No. 16 West-Indisch Wachtgeldbesluit 1925.

No. 17 Wijzigingen van enige bepalingen in de wetboeken omtrent wettelijk voorgeschreven bekendmakingen.

No. 32 Wijziging Rechterlijke Organisatie, waarbij door de Gouverneur aan de President en Leden van het Hof de waarneming van betrekking van Kanton- of Ommegaand Rechter kan worden opgedragen.

No. 43 Heffingen ten bate van het Immigratiefonds in Suriname.

1926 No. 37 Regeling van de salarissen van uit 's Landskas bezoldigde godsdienstleraren bij de Evangelische Broeder Gemeente.

No. 43 Immigratiebesluit 1926.

1927 No. 34 Verdeling Suriname in districten.

1927 No. 35 Organisatie van het Districtsbestuur. 
1928 No. 40 Regeling betreffende de benaming der districten.

No. 41 Regeling termijnen van dagvaarding.

1929 No. 79 Leprabesluit.

1932 No. 112 Wijziging Rechterlijke Organisatie betreffende de eisen van benoembaarheid rechterlijke ambtenaren.

1933 No. 2 Wijziging Delfstoffen- en Bauxiet verordening

3 in verband met het zakelijk recht op ontginning van delfstoffen.

1933 No. 94 Wijziging van het Wetboek van Strafrecht met betrekking tot misdrijven tegen de veiligheid van de Staat.

1933 No. 95 Bepalingen omtrent de uitoefening van het recht van vergadering.

No. 96 Bepalingen omtrent drukwerken.

1935 No. 79 Invoering van de Réchterlijke Organisatie, het

80 Surinaams Wetboek van Burgerlijke Rechtsvor-

81 dering en het Surinaams Faillissements besluit. 130

No. 102 Surinaams Luchtvaartbesluit.

1936 No. 78 Regeling in het belang van de koffiecultuur in Suriname.

No. 109 Herziening van het tarief van gerechtskosten en 110 salarissen in Burgerlijke- en Strafzaken.

No. 115 Invoering Surinaams Wetboek van Koophandel.

No. 116 Surinaams Strandvonderijbesluit.

No. 118 Eisen van benoembaarheid tot enkele functies in Suriname.

1937 No. 22 Wijziging en aanvulling Wetboek van Strafvordering.

1937 No. 32 Wijziging Begrafeniswerordening (begraven zonder kist).

Bij deze opsomming moge worden gevoegd:

1924 No. 49 Vernietiging door de Kroon van de verordening houdende bepalingen omtrent het vervallen van pensioenbijdragen.

No. 86 Intrekking door de Kroon van het besluit van 8 November 1922 (G.B. No. 87).

1934 No. 43 Vernietiging van een verordening tot wijziging en aanvulling van het Wetboek van Strafvordering t.a.v. de bewijskracht van getuigen- en deskundigen-verklaringen. 
Een enkele blik op deze lijst waarin slechts vermeld zijn de K.B.'s die interne aangelegenheden van Suriname regelen, toont aan dat een ruim gebruik is gemaakt van de bevoegdheid, bij artikel 48 Regeringsreglement toegekend.

Een bespreking van al deze gevallen zou te veel tijd eisen, wij moeten volstaan met een korte weergave van bezwaren, die naar aanleiding van enkele dier besluiten zijn naar voren gebracht.

De invoering bij K.B. van een bepaling om de opkoophuizen onder toezicht van de overheid te brengen nadat de Koloniale Staten een desbetreffend ontwerp hadden ontworpen, wekte terecht ontstemming, omdat de meerderheid van het College van oordeel was, dat de regeling van het pandhuiswezen bij een afzonderlijke verordening behoorde te geschieden en het bekend was, dat een der Statenleden een ontwerp daartoe voorbereidde. Een door de Staten in 1919 aangenomen initiatief ontwerp van mr S. D. DE VRIES, waarbij een Pandhuisverordening tot stand kwam, werd eerst in 1923 ingevoerd.

Waarom het West-Indisch verlofbesluit 1924, het West-Indisch Uitzendingsbesluit en de Wachtgeldenregeling bij K.B. werden ingevoerd zonder de Staten te horen, blijkt niet uit de stukken die voor het publiek te raadplegen zijn. Dachten Gouverneur en Opperbestuur dat het College al te vrijgeving zou zijn met voorrechten aan Surinaamse landsdienaren toe te kennen of was de differentiatie, die ten aanzien van uitgezonden ambtenaren en z.g. landskinderen werd gemaakt, de reden tot het uitlokken van een Koninklijk Besluit? Deze vraag is zonder inzage van correspondentie tussen Gouverneur en Minister niet te beantwoorden.

Onder dagtekening van 30 Juni 1923 werd door de Gouverneur bij de Koloniale Staten een ontwerpverordening aanhangig gemaakt tot wijziging van het Burgerlijk Wetboek en andere wettelijke regelingen hoofdzakelijk met de bedoeling te bevorderen dat de verschillende wettelijk voorgeschreven bekendmakingen, welke volgens het gebruikte stelsel in een der verschijnende nieuwsbladen geschiedde, in het Gouv. Adv. Blad te doen plaatsen. De Staten gingen met dit voorstel accoord, alleen waren zij van oordeel, dat aan een naamloze vennootschap het recht moest worden gelaten hare Statuten in het blad harer keuze te plaatsen. N.V.'s toch gaven meestal de voorkeur aan het publiceren in een blad, dat meer gelezen werd dan het G.A.B. Bij K.B. opgenomen in G.B. 1925 No. 17 werd de regeling ingevoerd, op grond dat 
de opneming in het officieel nieuwsblad van Suriname in het algemeen belang gewenst is en er geen aanleiding bestaat om voor Suriname een uitzondering te maken op het te dien aanzien in de Nederlandse, Nederlands-Indische en Curaçaose wetgeving aanvaard beginsel.

Misschien heeft tot dit K.B. bijgedragen de overweging dat de Staten het ontwerp verwierpen, omdat daardoor de belangen van de plaatselijke nieuwsbladen, waarvan enige redacteuren zitting in het College hadden, werden geschaad. Het nieuwsblad $D e W e s t$ schreef naar aanleiding van dit K.B. een artikel „,Ministeriële Plagerij”, waarin werd gezegd: „Nimmer is door een bewindsman in die mate misbruik gemaakt van de bevoegdheid in art. 48 Regeringsreglement aan de Kroon gegeven dan door Minister de Graaff."

De publicatie van 14 Mei 1925 (G.B. No. 32), waarbij de Rechterlijke Organisatie werd gewijzigd in dien zin, dat de Gouverneur bevoegd is de waarneming van de betrekking van Kanton- en Ommegaande Rechter op te dragen aan de President en leden van het Hof van Justitie, lokte veel protest uit. Het Hof van Justitie zond een adres aan de Kroon en in de 7e Jaargang van de $W$. I. Gids schreef A. S. J. Fernandes een artikel ,,Ministeriële bedreiging van onafhankelijkheid van het Opperste gerechtshof van Suriname".

In 1927 werd bij K.B. (G.B. 34 en 35) de verdeling van Suriname in districten en de organisatie van het Districts-Bestuur in Suriname geregeld, nadat de Staten een door Gouverneur van Heemstra gedaan voorstel hadden verworpen. Als gevolg dezer K.B.'s werden in 1928 (G.B. No. 40 en 41) twee Koninklijke Besluiten ingevoerd betreffende de benaming der districten en de termijnen in het Wetboek Burgerlijke Rechtsvordering, onderwerpen die zeer zeker tot de ,interne aangelegenheden" van Suriname behoren.

In een artikel in het nummer van 7 Mei 1930 van het onder redactie van de oud-Gouverneur $\mathrm{mr}$ A. J. A. A. baron vaN Heemstra staand Politiek en Economisch Weekblad wordt gezegd dat tegenstand in Suriname vaak aan kortzichtigheid is toe te schrijven. Als voorbeelden noemt de schrijver de actie tegen het overbrengen van het feestterrein van het Gouvernementsplein naar het Rietbergplein, het verzet tegen de Waterleiding en het verwerpen van de voorgestelde district-indeling. Het artikel eindigt: ,, ach begreep men in het algemeen maar beter wat waarachtig altruisme is en wat het beoogt, dan zou 
een groot deel van het historisch conservatisme daarvoor wijken".

Interessant is de geschiedenis van het Leprabesluit (G.B. 1929 No. 79). De Staten hadden in het ontwerp talrijke wijzigingen gebracht en fouten verbeterd, die door het Bestuur waren aanvaard.

Tenslotte konden Bestuur en Staten het niet eens worden over het verlangen van het College betreffende het zitting nemen van minstens twee particuliere geneesheren in de Lepracommissie en de wens van de Staten, dat de verordening 5 jaren na hare inwerkingtreding zou vervallen. Dit werd aanleiding om een K.B. uit te lokken.

Als merkwaardigheid moge het volgende worden aangetekend: Toen in 1930 een wijziging van het Leprabesluit werd voorgesteld, meenden enige leden van de Staten er bedenking tegen te moeten maken om tot goedkeuring daarvan mede te werken. Zij waren van oordeel, dat, daar de gouverneur uit hoofde van meningsverschil met de Staten niet t.a.v. hoofdbeginselen maar met betrekking tot punten van minder belang gemeend had te moeten bevorderen, dat de Lepraverordening niet is afgekondigd zoals door de Koloniale Staten goedgekeurd, zij bezwaar moesten maken om door goedkeuring van het ontwerp mede verantwoordelijkheid te aanvaarden voor een bestuursdaad, die door hen werd afgekeurd. De voorgestelde wijziging werd ten slotte met slechts $7-5$ stemmen aanvaard.

Waarom het Reglement op de inrichting en samenstelling der Rechterlijke macht in de Kolonie Suriname (G.B. 1932 No. 112) betreffende de vereisten om lid van de rechterlijke macht te worden bij K.B. is ingevoerd, blijkt nergens.

In het jaar 1933 werden door de Gouverneur een aantal verordeningen tot wijziging en aanvulling van het Wetboek van Strafrecht in hoofdzaak met betrekking tot het bepaalde omtrent misdrijven tegen de veiligheid van de Staat, de Openbare orde en het openbaar gezag, alsook omtrent de uitoefening van het recht van vergaderen, en drukwerken ingediend; deze bepalingen waren hoofdzakelijk ontleend aan de wet tot bestrijding van de revolutionaire woelingen in Nederland en de ,haatzaai" artikelen uit Nederlands Indië. De meerderheid der Staten makte vooral tegen de invoering van de laatstgenoemde artikelen bezwaar en wees er op, dat het beroep op het concordantie-artikel voor die artikelen van geen waarde was. De verordeningen werden dan ook door de Staten sterk geamendeerd, doch bij K.B. ingevoerd. In de vergadering van de Staten van 8 Januari 1934 
werd een motie van de heren MAY c.s. aangenomen waarin de Staten besloten hun leedwezen uit te spreken over de invoering der geamendeerde verordening bij K.B.

Buiten beschouwing kan worden gelaten de wijziging van de Delfstoffen en Bauxite verordening in 1933 (G.B. Nos. 2 en 3) in verband met het zakelijk recht van bauxite. Tegen deze technische wijziging heeft niemand bezwaar gemaakt.

In 1934 werd door de Kroon een door de Staten aangenomen en door de Gouverneur vastgestelde verordening tot wijziging en aanvulling van het Wetboek van Strafvordering hoofdzakelijk strekkende om de bewijskracht te regelen van ter terechtzitting voorgelezen verklaringen van getuigen en verslagen van deskundigen vernietigd, als in strijd met het algemeen belang (G.B. 1934 No. 43). Het Opperbestuur was van oordeel, dat dit ontwerp met het oog op de kosten, niet aanvaardbaar was en bij K.B. werd het Wetboek van Strafvordering gewijzigd. Tegen de invoering van de Nieuwe Rechterlijke Organisatie en de nieuwe Wetboeken van Burgerlijke Rechtsvordering Koophandel en het Faillissement werd scherp geprotesteerd. De Staten verwierpen mede op grond hiervan de begroting voor het dienstjaar 1937.

Met groot protest werd ook het K.B. van 13 Juli 1936 No. 47 (G.B. 1936 No. 118) ontvangen, waarin eisen voor benoembaarheid tot enkele functies in Suriname werden ongenomen. Vooral het feit, dat tot Districts-Commissarissen slechts benoembaar worden verklaard zij die geslaagd zijn in een van de doctorale examens van de Indologische studie, waardoor landskinderen die voorheen op grond van hun ervaring in de administratie en bestuursvoering tot dit ambt werden benoemd, voortaan uitgesloten waren, zette kwaad bloed.

Het laatste K.B. dat onder werking van artikel 48 werd ingevoerd is de wijziging van de Begrafenisverordening 1926. Het voorstel van de Gouverneur om voor de Nederlands-Indische immigranten en hun afstammelingen af te wijken van het voorschrift om lijken in een gesloten kist te begraven werd door de Staten niet noodzakelijk geacht, te meer omdat ruim 40 jaren na de invoering van de Javaanse Immigratie nooit bezwaren tegen het voorschrift waren ingebracht. Gevreesd werd, dat indien het ontwerp werd aangenomen van andere groepen der bevolking soortgelijke verzoeken zouden komen. Ook hier werd in een zuivere interne aangelegenheid de hulp van het Opperbestuur ingeroepen. 
Aan het voorgaande moge worden toegevoegd, dat het Opperbestuur in 1934 aan de gouverneur bevel gaf het Besluit van 8 November 1922 (G.B. 87) waarbij de rentestandaard van de Koloniale Postspaarbank door de gouverneur op 3\% p. j. was gebracht in te trekken.

De oud-griffier van de Koloniale Staten A. S. J. Fernandes schreef in Het Vaderland van 17 Dec. 1924 een artikel ,Ministerieel ingrijpen in interne bestuursaangelegenheden in Suriname" waarin hij tegen dit Koninklijk bevel protesteerde en o.m. schreef: „Maar bij het Departement van Koloniën schijnt nu eenmaal ten aanzien van Suriname alles mogelijk te zijn.'

De Staten namen een motie aan om hun leedwezen over het bevel uit te spreken, het Tweede Kamerlid Boon vroeg aan Minister DE GRAAFF inlichtingen over de zaak.

Het spreekt van zelf, dat in de loop der jaren de hantering van het beruchte artikel 48 niet zonder protest van de Staten en pers bleef en ook in de Kamers werden deze protesten vaak ondersteund.

Het zou te ver voeren een volledige opsomming te geven van de reactie van Staten en Kamerleden, doch het is - om een enkel voorbeeld te noemen - wel typisch, dat het Statenlid R. D. Simons in de vergadering van 5 Mei 1919 er op moest wijzen, dat de Minister de post van straatverbetering heeft geschrapt en zelfs zover is gegaan, dat een post voor een machineschrijfster op de Griffie van het College, waarvoor de reuze som van $f$ 414,was uitgetrokken, door de Minister van Koloniën van de begroting werd afgevoerd. Uit de parlementaire geschiedenis van de Staten mogen nog worden aangehaald de critiek van de Staten tegen de invoering van het Octrooi aan de Surinaamsche Bank (vergaderingen 5 en 10 Aug. 1918) en de motie, op 8 Mei 1919 door de Koloniale Staten aangenomen, waarin tot uitdrukking is gebracht dat de Minister van Koloniën, door verlaging van het traktement van de Griffier van de Staten, het College in hun bij Regeringsreglement gewaarborgde benoemingsrecht heeft bekort.

In de vergadering van 29 Juni 1918 werd op scherpe wijze gereageerd op de redevoering van het Tweede Kamerlid SibingA MUlder, naar aanleiding van het in verband met het Octrooi voor de Surinaamse Bank in de Staten aangevoerde en de houding van de Minister van Marine A. I. Rambonnet daartegen; de Statenleden traden als protest unaniem af. In Mei 1925 werd stelling genomen tegen de uitlating van de Minister van Finan- 
ciën dr H. Colijn, dat hij helemaal geen verwachting van Suriname had.

De objectiviteit gebiedt te vermelden, dat ook de Gouverneurs zich niet altijd neerlegden bij de beslissing van het „Plein in de Haag".

Bekend is, dat Gouverneur mr A. J. A. A. baron van HeEmstra in de Memorie van Toelichting op de begroting 1924 een scherpe critiek leverde op de verhouding Minister van Koloniën - Gouverneur van Suriname en de staf brak over het stelsel dat reeds jaren onafgebroken werd voortgezet.

Dit stelsel, waarbij — aldus de Gouverneur - het Opperbestuur formeel binnen de perken van zijn bevoegdheden handelde, is een der werkelijke rampen, waaronder Suriname zucht en welke haar geleidelijke ontwikkeling verhindert.

De vijf desiderata die Baron van HeEmstra aangaf om die verhouding te regelen zijn algemeen bekend. In de loop van de jaren hebben verscheidene Kamerleden de handschoen voor de Staten opgenomen. Zonder anderen te kort te doen mogen vooral $\mathrm{H}$. van Kol, J. W. IJZERMAN en DE Jong hier worden genoemd.

In Mei 1936 besloten de Staten de begroting 1937 niet op de gebruikelijke wijze te behandelen, slechts werd in een vergadering door enkele leden het woord gevoerd. De voorzitter-rapporteur zette uiteen, dat men algemeen van oordeel was, dat het vrijwel nutteloos was om de begroting diepgaand te behandelen, waar gebleken was dat men in Nederland geen prijs stelde op het oordeel der Staten: beschouwingen van dit College worden door het Opperbestuur genegeerd, belangrijke aangelegenheden Suriname betreffende, afgedaan zonder zelfs het oordeel der Surinaamse Volksvertegenwoordiging te vragen. Speciaal gewezen werd op de voorgenomen Rechterlijke reorganisatie en de hervorming van de Vaartuigendienst. Bij de verdediging van het ontwerp deed de Gedelegeerde van de Gouverneur een beroep op artikel 48 van het Regeringsreglement, betogende, dat formeel de bevoegdheid van het Opperbestuur om in te grijpen vaststaat.

Met 10 tegen 2 stemmen werd de begroting verworpen.

De invoering van de Surinaamse Staatsregeling op 1 April 1937 veranderde de toestand in theorie. Met gebruikmaking van de conflictenregeling werden ingevoerd: I. het Waterleidings- 
besluit (G.B. 1938 No. 33); II. het Dorpsgemeentebesluit (G.B. 1938 No. 66).

De geschiedenis van deze verordeningen moge hier - zeer in het kort - worden vermeld. Een door Gouverneur RUTGERS op 28 Februari 1930 aan de Staten ter goedkeuring aangeboden verordening, houdende verbodsbepalingen met betrekking tot watervergaarplaatsen, werd na een zeer lijvig voorlopig verslag van de Staten, waarin talrijke bezwaren werden ontwikkeld, speciaal ten aanzien van de draagkracht van bepaalde bevolkingsgroepen en de hoogte der tarieven, door de Staten op 8 April 1937 verworpen. Reeds op 29 April van dat jaar werd de verordening opnieuw door Gouverneur KIELSTRA aangeboden en in de vergadering van 28 Juni 1937 werd zij weer verworpen. Bij K.B. van 22 Februari 1938 werd krachtens artikel 100 derde lid der Surinaamse Staatsregeling het „Waterleidingsbesluit” vastgesteld.

Geheel anders is de geschiedenis van het Dorpsgemeentebesluit. De Staten hadden in het ontwerp een wijziging gebracht, tot strekking hebbende instelling, wijziging en opheffing van een dorpsgemeente bij verordening te doen geschieden en niet bij besluit, zoals de Gouverneur had voorgesteld, welk voorstel het College in strijd met de Staatsregeling achtte. De Gouverneur, gebruik makende van de hem bij de Staatsregeling toegekende bevoegdheid, kondigde de verordening op eigen gezag en verantwoordelijkheid af. De Staten, gebruik makende van de bevoegdheid hun in het derde lid van artikel 101 van de Surinaamse Staatsregeling toegekend, wendden zich tot de Kroon en hadden volledig succes. Het Opperbestuur stelde de verordening bij Algemene maatregel van bestuur vast, in overeenstemming met de zienswijze der Staten. Politiek had deze overwinning geen gevolgen; de Gouverneur bleef aan.

Op 10 Mei 1940 trad de oorlogstoestand in, als gevolg waarvan de Gouverneur, gebruik makende van het recht hem toegekend in artikel 31 en 32 der Staatsregeling, verschillende „Maatregelen" invoerde.

Ontstemming verwekte de invoering van de Aziatische Huwelijksverordeningen (G.B. 1940 No. 149 en 150), die tot twee malen door de Staten verworpen waren, alsmede de overgang van bevoegdheden welke aan de Commissaris van Politie en andere autoriteiten toekwamen, op de Districts-Commissaris van Paramaribo (G.B. 1940 No. 70).

Over de vraag of de Gouverneur een juist gebruik van zijn 
macht heeft gemaakt door het uitvaardigen van de maatregelen krachtens genoemde artikelen, zijn interessante beschouwingen geleverd. Hierop kan in dit artikel niet worden ingegaan.

Ook nu eenzijdige regeling bij K.B. onmogelijk is, zullen in de toekomst conflicten tussen Bestuur en Staten niet uitblijven. De behandeling van het Kiesreglement in 1948 heeft dit wel aangetoond. Geruststellend is daarbij, dat Gouverneur HUENDER op 8 December 1948 aan de Staten schreef, dat geen stappen zullen worden genomen om dit reglement bij Algemene Maatregel van Bestuur te doen vaststellen en daaraan toevoegde: „De motieven, welke tot deze beslissing leidden, zijn vooral en met name te vinden in de overtuiging, welke ook bij mij leeft, dat het tijdstip is aangebroken, waarbij inwendige aangelegenheden behoren te worden geregeld door de locale Surinaamse Wetgever, zelfs al bestaat niet in alle opzichten overeenstemming van inzichten."

\section{SUMMARY}

The author states that Suriname now being autonomous, in as much as regards the internal affairs of the country, government by Royal Decree is now a thing of the past.

A. J. J. DE NEEF when upholding in 1915 his thesis at the Leiden University, gave a summary of cases in which the Royal Government acted as legislator in regard to internal affairs of Suriname. In the present article DE NEEF's survey is supplemented by the cases after 1945; at the same time the legal basis of the intervention-is explained. A summary follows of all Royal Decrees put into effect in Suriname from the year 1915 until the year 1937, with the history and back ground of some of them.

How the local representative body in many cases took exception to this intervention is related in this article, as also how Governor van HeEmstra exposed the evils which arose from the peculiar interrelation between the minister of the crown for the Colonies and the representative of the Crown abroad.

Two other governors are mentioned, prof. Kielstra in regard to a conflict during his administration and dr HUENDER as an advocate of homerule for Suriname, in all matters of internal character. 